\title{
Enabling low latency video distribution directly on the physical layer in passive optical networks
}

Suhr, L. F.; Vegas Olmos, Juan José; Estaran Tolosa, Jose Manuel; Tafur Monroy, Idelfonso

Published in:

ACP/IPOC 2013

Publication date:

2013

Document Version

Publisher's PDF, also known as Version of record

Link back to DTU Orbit

Citation (APA):

Suhr, L. F., Vegas Olmos, J. J., Estaran Tolosa, J. M., \& Tafur Monroy, I. (2013). Enabling low latency video distribution directly on the physical layer in passive optical networks. In ACP/IPOC 2013 [AF1G.2] Optical Society of America.

\section{General rights}

Copyright and moral rights for the publications made accessible in the public portal are retained by the authors and/or other copyright owners and it is a condition of accessing publications that users recognise and abide by the legal requirements associated with these rights.

- Users may download and print one copy of any publication from the public portal for the purpose of private study or research.

- You may not further distribute the material or use it for any profit-making activity or commercial gain

- You may freely distribute the URL identifying the publication in the public portal 


\title{
Enabling low latency video distribution directly on the physical layer in passive optical networks
}

\author{
L.F. Suhr, J.J. Vegas Olmos, J. Estaran, and I. Tafur Monroy \\ Department of Photonics Engineering, Technical University of Denmark, Ørsted Plads 343, Kgs. Lyngby, 2800, Denmark \\ jjvo@fotonik.dtu.dk
}

\begin{abstract}
We report on a dual system in which one uncompressed HD video channel and a 10 Gbps duobinary signal are simultaneously transmitted using a single O-band VCSEL over different types and length of fibers.
\end{abstract}

OCIS codes: (060.2330) Fiber optics communications; (060.4080) Modulation.

\section{Introduction}

Video-based traffic arguably occupies most of the bandwidth in current networks, and is projected to grow even more [1]. Estimates indicate that internet video traffic will constitute $55 \%$ of the global consumer internet traffic in 2016, from 51\% in 2011. Furthermore, the sum of all forms of video (TV, video on demand (VoD), internet, and peer-to-peer (P2P)) will cover approximately $86 \%$ of the worldwide traffic by 2016 . VoD presents a feature that impacts the network: by 2016, high-definition (HD) internet video will comprise $79 \%$ of VoD. This forceful forecast urges to reduce the traffic load over the link layer by devising solutions that move the VoD traffic to dedicated physical channels, specifically in the access segment, where the main bottleneck resides. Previous work includes employing P2P capable optical access networks based on optical switches [2]. However, this solution would require migrating from current cost-effective passive optical networks (PON) to active optical networks (AON).

Alternatively, solutions to multiplex two HD video signals over a single laser source to later feed a PON system has been also proposed [3]. Nevertheless, the end users require also regular Ethernet channels for other traffic demanding apparel, such as desktop computers, laptops, game consoles and so on.

We propose to simultaneously multiplex a 10Gbit/s baseband signal and a HD video placed in a subcarrier to drive a single laser source for PON distribution. Figure 1 shows our target scenario. Ethernet based services can be transported using the baseband, as in regular PON systems, whereas video based services such as VoD, online gaming, or video conferencing, are transported in a dedicated subcarrier. By splitting the physical transport of the signals according to their video nature, we enable low latency video distribution since HD signals can now be directly fed into displaying modules, thereby reducing the traffic congestion on the upper layers.

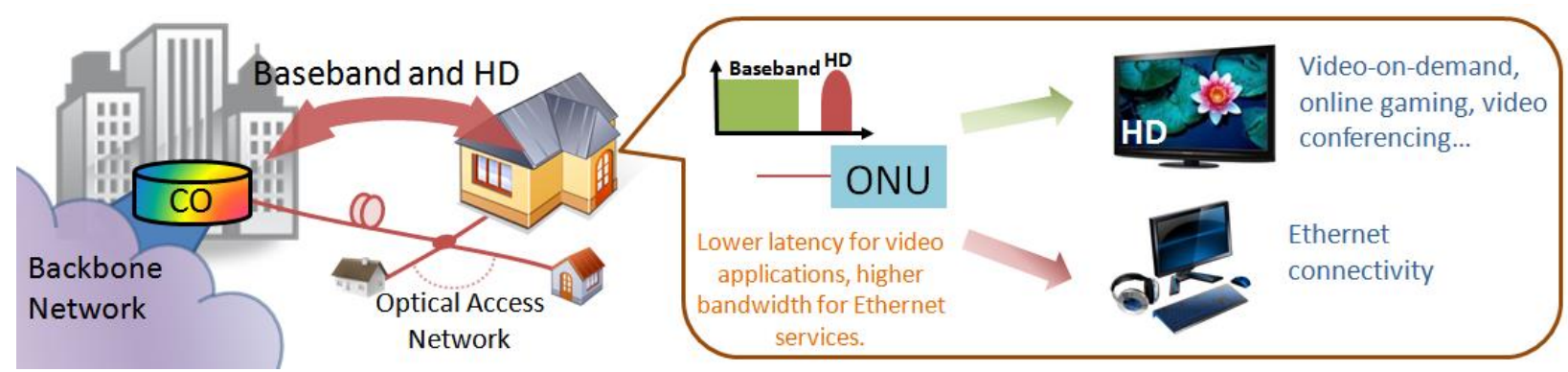

Fig. 1. Network scenario for optical access network with direct distribution of video services. CO: central office. ONU: optical network unit.

Access networks are very cost sensitive, and hence, cost-effective solutions for such distribution need to be engineered. Among the existing technologies, vertical-cavity surface-emitting lasers (VCSELs) are considered a viable solution to optical laser sources, because they provide a substantial operational bandwidth, low power consumption and low driving voltage, which in turn offers relax dissipation requirements, high array integrability along with low manufacturing costs. These features make VCSELS perfectly suitable as laser sources for costsensitive networks as those in the access segment [4]. 
In this paper we present a baseband and an HD-channel dual system employing low-driving voltage 10Gbit/s class VCSELs operating at O-band. The baseband signal conveys 10Gbit/s but bandwidth reduction is achieved by the use of spectral efficient duobinary modulation.

\section{Modulation choice and Experimental demonstration}

Optics beyond 10Gbps are currently out of budget for mass deployment in access scenarios. Therefore, the only viable alternative to increase the capacity while keeping the deployed equipment is to increase the spectral efficiency of the signals conveying the data. Duobinary signaling is a partial-response transmission format that makes use of controlled inter-symbol interference (ISI) to induce correlation among the bits to reduce the spectral width [5]. Although other advanced modulation formats offer better spectral efficiency, duobinary has the advantage of generating only three levels, and therefore, there is less complexity in the receiver side [6]. The experimental setup is shown in Figure 2.

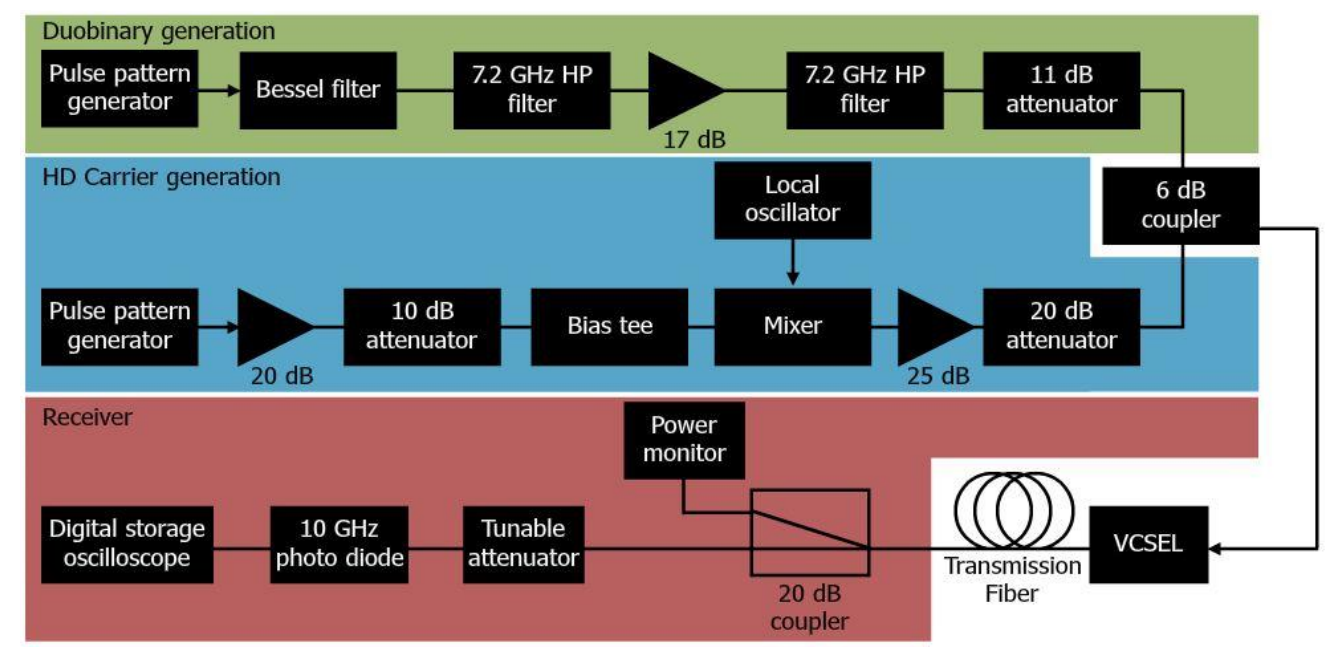

Fig. 2. Experimental setup. HP: High-pass filter

The laser utilized was an O-band VCSEL working at $1281 \mathrm{~nm}$ with a 3-dB modulation bandwidth of $10 \mathrm{GHz}$ at room temperature. The measured output power at $11 \mathrm{~mA}$ bias current was $0 \mathrm{dBm}$.

In the duobinary transmitter, a pulse pattern generator (PPG) was used to generate a $10 \mathrm{Gbps}$ signal. The signal was passed through a $5^{\text {th }}$ order Bessel filter with $3.25 \mathrm{GHz}$ cutoff frequency to generate the duobinary signal. The following high-pass filters were used to remove the high frequency components of the duobinary signal and the out of band noise from the amplifier. The attenuators and amplifiers were used to both match and maximize the output peak-to-peak voltage to the input range of the VCSEL. For the HD signal generation, we used a second PPG to generate a $1.25 \mathrm{Gbps}$ signal. The following amplifier and attenuator were used to match the signal's peak-to-peak power to the optimum power level of the mixer while also reducing reflections. The local oscillator (LO) was set to $7 \mathrm{dBm}$ at $7 \mathrm{GHz}$. The following amplifier and attenuator were again used to match the input threshold of the VCSEL and to reduce reflections in the system. The PPG in the duobinary transmitter was also used to generate a $2.5 \mathrm{Gbps}$ signal to assess the performance of the Bessel filtering effect is implemented in a low speed setup. The signal was then transmitted through different links of 5-, 10- and 20-km standard single mode fiber (SMF), dispersion shifted fiber (DSF) and non-zero dispersion shifted fiber (NZDSF) to emulate diverse deployed types of access networks. The received signal was sampled and stored with a $13 \mathrm{GHz}$ bandwidth, $40 \mathrm{Gs} / \mathrm{s}$ digital storage oscilloscope (DSO) for later demodulation with digital signal processing (DSP).

Figure 3 shows the experimental results. Bit error rate (BER) curves as a function of input optical power are presented. Figure 3(a) shows the performance for the $2.5 \mathrm{Gbps}$ signal and Figure 3(b) shows the performance of the $10 \mathrm{Gbps}$ duobinary signal. As insets, captured eye diagrams of some representative cases are depicted. The impact of the Bessel filter with $3.25 \mathrm{GHz}$ cutoff on a NRZ signal at $2.5 \mathrm{Gbps}$ is negligible, and therefore the system can work at both bitrates without any topology change. The transmission performance of the 2.5 Gbps NRZ signal remains within $1 \mathrm{~dB}$ penalty and error floor is not observed. The sensitivity of the 1.25G HD signal is 4-dB worst 
than the $2.5 \mathrm{G}$ baseband, due to the penalty introduced by the electrical mixer, which degrades the quality of the signal.

For the 10 Gbps case (Fig.3(b)), it is shown error-free transmission for the three fiber types up to $10 \mathrm{~km}$ after forward error correcting (FEC) decoding. Post-FEC error-free transmission is observed for all the cases above - 12 $\mathrm{dBm}$ of received optical power. The sensitivity difference with respect to the worst case never exceeds $2 \mathrm{~dB}$, which indicates the suitability of duobinary modulation for a variety of deployed access links.
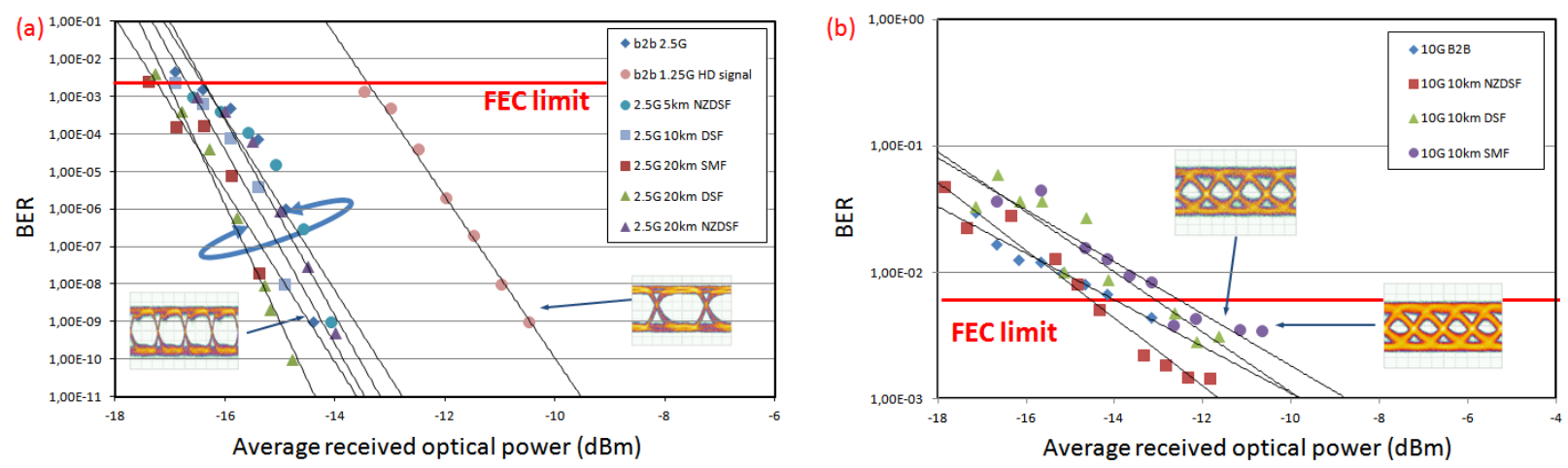

Fig. 3: BER performance for the transmitter operating at $2.5 \mathrm{Gbps}$ (a) and $10 \mathrm{Gbps}$ in the duobinary mode (b).

\section{Conclusions}

Uncompressed HD video distribution needs to be addressed employing already deployed PON links supporting different type of optical fibers. Distributing HD signals directly to the end users on a different channel than the baseband providing regular connectivity is a way to alleviate restrictions in terms of latency and capacity. In this paper, we assessed how VCSELs can be used efficiently for such purpose and experimentally demonstrated successful simultaneous transmission of a $2.5 \mathrm{Gbps} \mathrm{NRZ}$ or a $10 \mathrm{Gbps}$ duobinary baseband signal together with a 1.25 Gbps signal employing a single 10Gbps class device.

\section{References}

[1] Cisco Visual Networking Index: Forecast and Methodology, 2012-2017, http://www.cisco.com/en/US/solutions/collateral/ns341/ns525/ns537/ns705/ns827/white paper_c11-481360.pdf

[2] J. J. Vegas Olmos, T. Kuri, T. Sono, K. Tamura, H. Toda, and K. Kitayama, "Wireless and optical-integrated access network with peer-topeer connection capability," IEEE PTL 20, 1127-1129 (2008).

[3] J.M. Estaran, J.J. Vegas Olmos, G.A. Rodes, and I. Tafur Monroy, "Bidirectional uncompressed HD video distribution over fiber employing VCSELs," IEEE Photonics Conference (IPC), 30-31 (2012).

[4] Terence Quinlan, Sandra Dudley, Maria Morant, Roberto Llorente, and Stuart Walker, "VCSEL-based, CWDM - PON systems using reflective technology for bi-directional multi-play service provision," Opt. Express 20, 16726-16734 (2012) http://www.opticsinfobase.org/oe/abstract.cfm?URI=oe-20-15-16726

[5] A. Lender, "Correlative digital communication techniques," IEEE Trans. on Communication Technology, 128-135 (1964).

[6] M. Joindot, G. Bosco, A. Carena, V. Curri, and P. Poggiolini, "Fundamental performance limits of optical duobinary," Opt. Express 16, 19600-19614 (2008)

http://www.opticsinfobase.org/oe/abstract.cfm?URI=oe-16-24-19600

\section{Acknowledgements}

J.J. Vegas Olmos acknowledges the Marie Curie program for partly funding this research through the WISCON project. 